\title{
A STUDY OF DISTAL RENAL TUBULAR FUNCTIONS BY A MODIFIED STOP FLOW TECHNIQUE
}

\author{
By JOHN R. JAENIKE AND ROBERT W. BERLINER WITH THE TECHNICAL ASSISTANCE OF \\ AGNES SCOTT PRESTON
}

(From the Laboratory of Kidney and Electrolyte Metabolism, National Heart Institute, National Institutes of Health, Bethesda, Md.)

(Submitted for publication September 14, 1959; accepted October 9, 1959)

The stop flow technique has afforded a relatively simple method for the localization of certain renal tubular functions (1-3). However, as previously indicated by Pitts, Gurd, Kessler and Hierholzer (2), the method has certain technical shortcomings. As a result of contamination of initial specimens by preformed urine in the renal pelvis, admixture of specimens in the pelvis during outflow, and variations in nephron length, some lack of precision in localization is inevitable. In addition, water reabsorption in the distal tubular system may lead to displacement of the intratubular fluid column toward a more distal site (4), and consequently distort the various concentration patterns. This latter process is minimized, however, during mannitol diuresis, because of the limited movement of water out of the tubular lumen $(5,6)$. Finally, any specimen trapped within the tubule, proximal to the terminal collecting duct, may be modified during its subsequent passage through the nephron after release of ureteral occlusion. Consequently, accurate quantification of the movements of water and electrolytes, particularly in specimens derived from the proximal tubule, is impossible.

In the present study, attention has been focused on events which occur in the distal portion of the tubular system, the collecting ducts and the distal convolutions, during the period of stop flow. Experiments have been conducted during water, sodium chloride, sodium sulfate, and mannitol diuresis. This has permitted the testing of certain previously proposed hypotheses derived from stop flow experiments performed exclusively during mannitol diuresis. Investigation of the concentrating mechanism has also been possible, a procedure largely precluded in stop flow experiments conducted during hypertonic mannitol diuresis.

The dead space within the renal pelvis, comprising 2 to $3 \mathrm{ml}$ of urine, considerably distorts the concentration patterns in specimens from the distal tubular segments. This is partially offset in experiments performed during mannitol diuresis because of the large volume of fluid (up to $20 \mathrm{ml}$ ) obtained prior to the appearance of new glomerular filtrate. Thus each tubular segment has a large volume representation in the collected outflow. During water or sodium chloride diuresis, however, in which the comparable volume is of the order of 3 to $7 \mathrm{ml}$, the pelvic dead space constitutes a major restriction to accurate studies. Consequently, a means of eliminating this dead space has been devised, and is utilized in the present experiments. In addition, a method for labeling fluid from the region of the distal convoluted tubule (analogous to the use of para-amino hippurate to tag proximal urine) has been utilized in order to obtain more precise localization of the various distal tubular functions. Data concerning the relative locations and interrelationships of sodium, chloride, potassium, and water movements have been obtained.

\section{METHODS AND PROCEDURE}

With the exception of the modifications to be described, the basic technique as first proposed by Malvin, Sullivan and Wilde was employed (7). All experiments were performed on female mongrel dogs, anesthetized with intravenous pentobarbital or thiopental. The latter was used in all experiments in which a water diuresis was produced (8).

The left ureter was catheterized through a flank incision. The pelvic dead space was obliterated by the following procedure. At the time of operation, the shaft of a short no. 23 needle, attached to a length of no. 50 polyethylene tubing (Intramedic), was inserted through the renal parenchyma into the kidney pelvis. The pelvic catheter was led out through the skin incision, which was closed with clips. Just prior to the time of occlusion the ureteral catheter was attached to a needle on a stopcock (stopcock no. 1 in Figure 1) and the urine was allowed to escape through the side arm. As. shown in Figure 1, the other end of this stopcock (no. 1) was attached to an- 


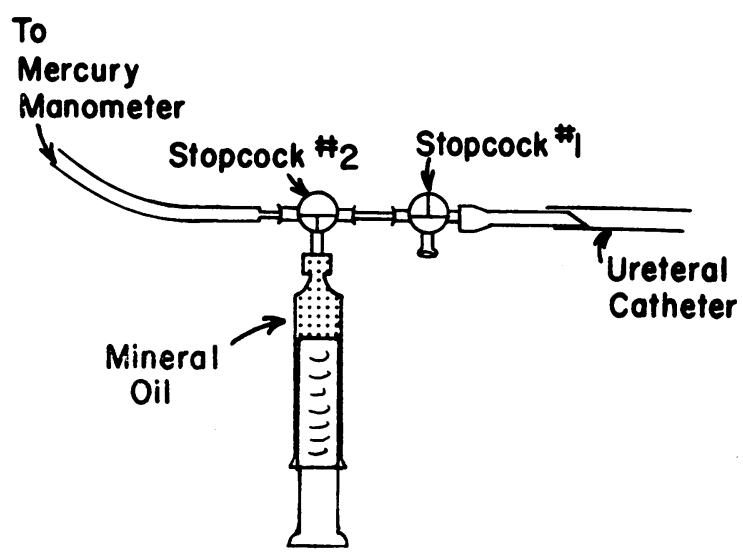

Fig. 1. Apparatus USED FOR URETERAL OCClusion.

other stopcock (no. 2) which had been modified so that all three openings intercommunicated freely. To the side arm of stopcock no. 2 was attached a syringe filled with mineral oil, stained with Sudan Black. The distal opening was connected to a mercury manometer. Immediately prior to stopping flow, $20 \mathrm{ml}$ of air was rapidly injected into the pelvic catheter and allowed to escape through the side arm of stopcock no. 1. This served to wash the urine out of the renal pelvis and ureteral catheter. Stopcock no. 1 was then turned so that the ureteral catheter communicated with stopcock no. 2, and mineral oil was injected from the syringe until a pressure of 100 to $110 \mathrm{~mm}$ of mercury was attained. This procedure was completed within five seconds of starting the air washout. Any residual air or urine within the renal pelvis was allowed to reflux through the pelvic catheter, which was clamped when only mineral oil was refluxing. The above pressure was maintained throughout the stop flow period, thus preventing entrance of newly formed urine into the pelvis from the kidney.

At the time the flow was started, the initial urine was collected by allowing it to pass serially into several lengths of no. 200 polyethylene tubing. Approximately the first $2.0 \mathrm{ml}$ of urine was collected in this fashion. Subsequent $0.5 \mathrm{ml}$ samples were collected in small test tubes. The initial urine was easily distinguished from the colored mineral oil, with which it was often admixed. Serial $0.17 \mathrm{ml}$ specimens were removed from the tubing by measuring the proper fluid column lengths, clamping and cutting the tubing, and transferring the specimens to small plastic containers.

In order to localize the concentration patterns observed in relation to the distal convoluted tubule, an attempt was made to label the urine contained within the renal cortex during the occlusion period. A small (no. 23) needle tip connected to a length of no. 50 polyethylene tubing was introduced into the superficial renal cortex at the time of operation. The needle was passed along under the kidney capsule, about $2 \mathrm{~mm}$ below the surface, and remained in situ throughout the balance of the experiment. During the occlusion period, one minute prior to starting the flow, 50 to $100 \mu \mathrm{c}$ of $\mathrm{K}^{42} \mathrm{Cl}$ contained in not more than $0.1 \mathrm{ml}$ of water was injected through the catheter into the renal parenchyma. The stop flow specimens were subsequently counted in a well-type scintillation counter. It was postulated that a portion of the injected $\mathrm{K}^{2}$ would diffuse into the adjacent renal tubules during the one minute period prior to starting the urine flow, and that the isotope would thus label urine contained within the contiguous renal cortex during the occlusion period. The absence of isotope in the first specimens collected indicated that these came from the medullary or inner cortical portion of the distal tubular system. As shown in Figures 3 and 4, the $\mathrm{K}^{2}$ appeared in a sharp peak and then diminished, presumably because of more rapid urinary transit through the area containing the isotope, and because of removal of isotope in the renal circulation.

In all experiments, inulin was infused at a constant rate for at least one hour prior to ureteral occlusion. Creatinine was injected intravenously one minute before starting flow, in order to label new glomerular filtrate (1). Specimens were analyzed for freezing point de-

TABLE I

Changes in osmolality and inulin concentration in stop flow experiments conducted during water diuresis*

\begin{tabular}{|c|c|c|c|c|c|c|c|c|c|}
\hline \multirow[b]{2}{*}{ Dog } & \multirow[b]{2}{*}{ Weight } & \multicolumn{2}{|c|}{ Sustaining infusion } & \multicolumn{3}{|c|}{ Free urine flow } & \multicolumn{2}{|c|}{$\begin{array}{l}\text { Stop flow } \\
\text { maximum values }\end{array}$} & \multirow[b]{2}{*}{$\begin{array}{c}\text { Plasma } \\
\text { osmolality }\end{array}$} \\
\hline & & Rate & $\begin{array}{c}\text { Composi- } \\
\text { tion }\end{array}$ & Rate & $\underset{\text { inulin }}{\mathrm{U} / \mathrm{P}}$ & $\mathrm{U}_{\mathrm{os}}$ & $\underset{\text { inulin }}{\mathrm{U} / \mathrm{P}}$ & Uos & \\
\hline & $k g$ & $m l / \min$ & $m E q / L$ & $\mathrm{ml} / \mathrm{min}$ & & & & & \\
\hline $\mathrm{B}$ & 16.3 & 4.0 & $\begin{array}{l}30 \mathrm{NaCl} \\
10 \mathrm{KCl}\end{array}$ & 3.95 & 11.8 & 39 & 114 & 234 & 299 \\
\hline I & 9.7 & 3.7 & $\begin{array}{l}60 \mathrm{NaCl} \\
10 \mathrm{KCl}\end{array}$ & 2.52 & 15.0 & 153 & 126 & 419 & 267 \\
\hline $\mathrm{R}$ & 13.7 & 7.3 & $\begin{array}{l}30 \mathrm{NaCl} \\
10 \mathrm{KCl}\end{array}$ & 5.54 & 7.5 & 52 & 111 & 286 & 263 \\
\hline
\end{tabular}

${ }^{*}$ Each dog received an initial intravenous water load (2.5 per cent glucose in water) of 3.0 to 3.7 per cent of body weight. 
TABLE II

Changes in urine osmolality during ureteral occlusion in water loaded dogs infused with isotonic electrolyte solutions*

\begin{tabular}{|c|c|c|c|c|c|c|}
\hline \multirow[b]{2}{*}{ Dog } & \multicolumn{2}{|c|}{ Sustaining infusion } & \multicolumn{2}{|c|}{ Free urine flow } & \multirow{2}{*}{$\begin{array}{c}\text { Plasma } \\
\text { osmolality }\end{array}$} & \multirow{2}{*}{$\begin{array}{c}\text { Stop flow } \\
\text { Maximum } \\
\text { Uos }\end{array}$} \\
\hline & Rate & Composition & Rate & Uos & & \\
\hline $\mathrm{D}$ & $\begin{array}{l}m l / m i n \\
6.0\end{array}$ & $\begin{array}{c}m E q / L \\
120 \mathrm{NaCl} \\
20 \mathrm{KCl}\end{array}$ & $\begin{array}{l}\mathrm{ml} / \mathrm{min} \\
5.0\end{array}$ & 150 & 285 & 328 \\
\hline $\mathrm{E}$ & 6.0 & $\begin{array}{r}110 \mathrm{NaCl} \\
30 \mathrm{KCl}\end{array}$ & 4.15 & 165 & 282 & 414 \\
\hline$F$ & 6.0 & $\begin{array}{l}80 \mathrm{NaCl} \\
60 \mathrm{KCl}\end{array}$ & 4.70 & 202 & 273 & 579 \\
\hline
\end{tabular}
weight.

* Each dog received an initial intravenous water load (2.5 per cent glucose in water) of 3.9 to 4.1 per cent of body

pression, and for concentrations of inulin, creatinine, sodium, potassium, and chloride. Plasma electrolytes, osmolality, and inulin concentration were also determined. Blood was withdrawn just prior to or immediately after the occlusion period. For the sake of uniformity a stop flow period of eight minutes was utilized in all experiments reported herein. Two control (free flow) clearance periods were collected immediately before and shortly after each stop flow period.

Two groups of dogs were given initial intravenous water loads, and subsequently infused with either hypotonic or isotonic electrolyte solutions. The infusion data from these studies are detailed in Tables I and II. The procedure on animals given hypertonic sodium chloride solution is summarized in Table III. Two dogs were given sodium sulfate, 120 mmoles per $\mathrm{L}$, and potassium chloride, $40 \mathrm{mEq}$ per $\mathrm{L}$, at rates of $6.0 \mathrm{ml}$ per minute. Each also received acetazolamide; a $100 \mathrm{mg}$ priming dose, one hour before stopping flow, and a sustaining dose of $10 \mathrm{mg}$ per $\mathrm{kg}$ of body weight per hour.

Urine and plasma osmolality was determined by the method of Bowman, Trantham and Caulfield (9). A special adapter was used for determinations of the 0.17 $\mathrm{ml}$ samples. Inulin, creatinine, and electrolytes were measured by methods previously outlined for this laboratory $(10)$.

\section{RESULTS}

\section{Osmolality and inulin concentrations}

A. Water diuresis. Figure 2 depicts the results of an eight minute period of stop flow performed during a brisk water diuresis. In the first specimen collected, representing the most distal portion of the tubular system, osmolality and the urine to plasma concentration ratio for inulin (hereafter designated as U/P inulin) are markedly increased above the corresponding free flow (control) levels. Both values decrease sharply in specimens from less distal segments of the tubule. The concentration curves, plotted on a proportional scale, diminish in a parallel fashion in specimens derived from the distal tubular segments. An essentially identical pattern has been observed in two other dogs similarly water loaded and infused with hypotonic electrolyte solutions. Maximal osmolality and $\mathrm{U} / \mathrm{P}$ inulin always appeared in specimens from the most distal tubular segment. These data are summarized in Table I.

TABLE III

Changes in osmolality and inulin concentration in stop flow experiments conducted during sodium chloride diuresis

\begin{tabular}{|c|c|c|c|c|c|c|c|c|c|}
\hline \multirow[b]{2}{*}{ Dog } & \multirow[b]{2}{*}{ Weight } & \multirow[b]{2}{*}{$\begin{array}{l}\text { Infusion* } \\
\text { rate }\end{array}$} & \multicolumn{3}{|c|}{ Free urine flow } & \multirow[b]{2}{*}{$\begin{array}{c}\text { Plasma } \\
\text { osmolality }\end{array}$} & \multicolumn{2}{|c|}{$\begin{array}{l}\text { Stop flow } \\
\text { maximum values }\end{array}$} & \multirow{2}{*}{$\begin{array}{c}\text { Site of } \\
\text { maximal } \\
\text { U/P inulin }\end{array}$} \\
\hline & & & Rate & $\underset{\text { inulin }}{\mathrm{U} / \mathrm{P}}$ & Uos & & $\begin{array}{c}\mathrm{U} / \mathrm{P} \\
\text { inulin }\end{array}$ & Uos & \\
\hline & $k g$ & $m l / m i n$ & $m l / \min$ & & & & & & $\%$ \\
\hline $\begin{array}{l}\mathrm{C} \\
\mathrm{G} \\
\mathrm{M}\end{array}$ & $\begin{array}{l}14.3 \\
10.7 \\
11.9\end{array}$ & $\begin{array}{l}6.0 \\
4.0 \\
6.0\end{array}$ & $\begin{array}{l}3.26 \\
3.40 \\
5.25\end{array}$ & $\begin{array}{r}14.4 \\
7.4 \\
5.4\end{array}$ & $\begin{array}{l}346 \\
256 \\
314\end{array}$ & $\begin{array}{l}300 \\
330 \\
301\end{array}$ & $\begin{array}{r}118 \\
89 \\
89\end{array}$ & $\begin{array}{l}548 \\
463 \\
507\end{array}$ & $\begin{array}{l}32 \\
28 \\
38\end{array}$ \\
\hline
\end{tabular}

* Infusion of sodium chloride, $200 \mathrm{mEq}$ per $\mathrm{L}$. 


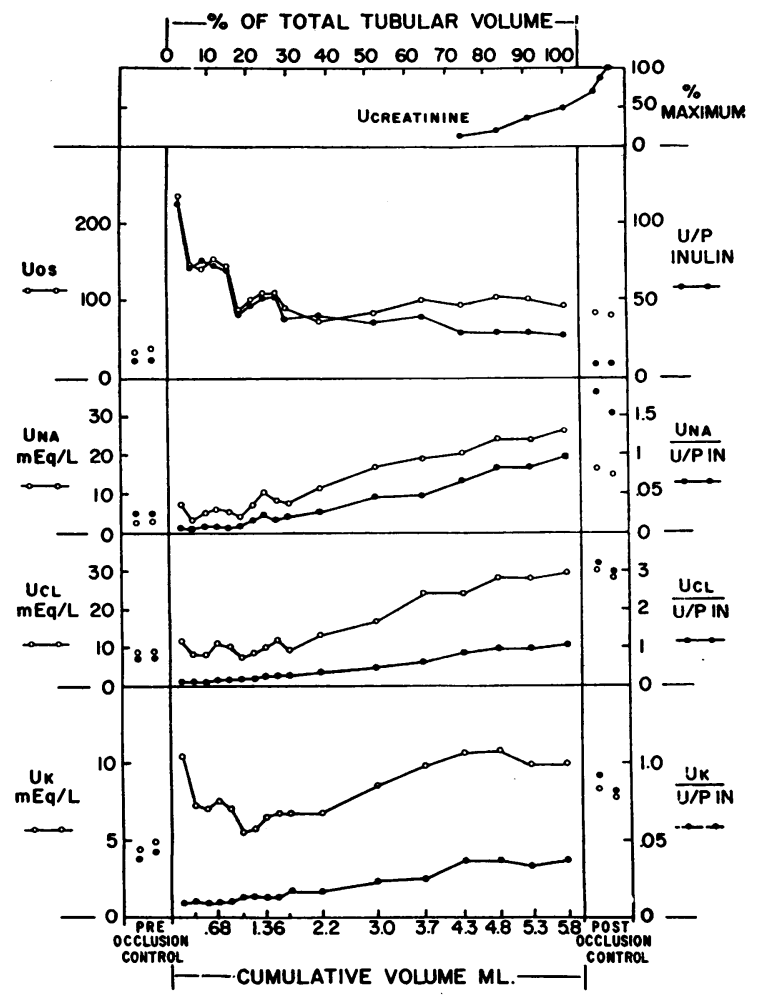

Fig. 2. Stop FLOW STUdy CONDUCTEd DURING WATER DIURESIS (DOG B). In this and subsequent figures, the most proximal stop flow specimen is arbitrarily designated as that which contained approximately 50 per cent of the peak concentration of creatinine (2). Subsequent specimens represent predominantly new glomerular filtrate, and are not plotted. The total cumulative volume, plotted along the lower abscissa, includes the most proximal specimen, according to the above designation. For the sake of comparison between studies, the cumulative volume is divided into percentages of total volume, and plotted along the upper abscissa.

Maximal osmolality achieved during stop flow varied, but appeared to be directly related to the previous control urine osmolality. A similar relationship was observed in three other dogs which were initially water loaded and subsequently infused with isotonic electrolyte solutions (Table II), and in dogs infused with hypertonic sodium chloride solution (Table III).

$B$. Solute diuresis. Three dogs were infused with hypertonic sodium chloride solution (200 $\mathrm{mEq}$ per L) and stop flow performed when a solute diuresis had been established. A representative experiment is shown in Figure 3, and the data from all experiments are summarized in Table III. In each case urine osmolality was maximal in the most distal specimen. Only a gradual fall in osmolality occurred in specimens from the more proximal segments of the tubule. The pattern of $\mathrm{U} / \mathrm{P}$ inulin concentration differed strikingly from that observed during water diuresis. A maximum concentration does not occur in the most distal specimen. There is instead a marked concentration peak in specimens from a more proximal portion of the tubular system (Figure 3). This has been a constant finding in all dogs infused with hypertonic sodium chloride solution, and presumably secreting endogenous vasopressin. As shown in Table III, the $U / P$ inulin peak appears when between 28 and 38 per cent of the total fluid, up to the appearance of new glomerular filtrate, has been collected. A less striking and more diffuse peak was observed following ureteral occlusion performed during infusion of 120 mmoles per $\mathrm{L} \mathrm{Na} \mathrm{SO}_{4}$ (Figure 4), and 2 per cent mannitol with $200 \mathrm{mEq}$ per $\mathrm{L} \mathrm{NaCl}$. This peak was virtually absent during hypertonic mannitol diuresis (Figure 5).

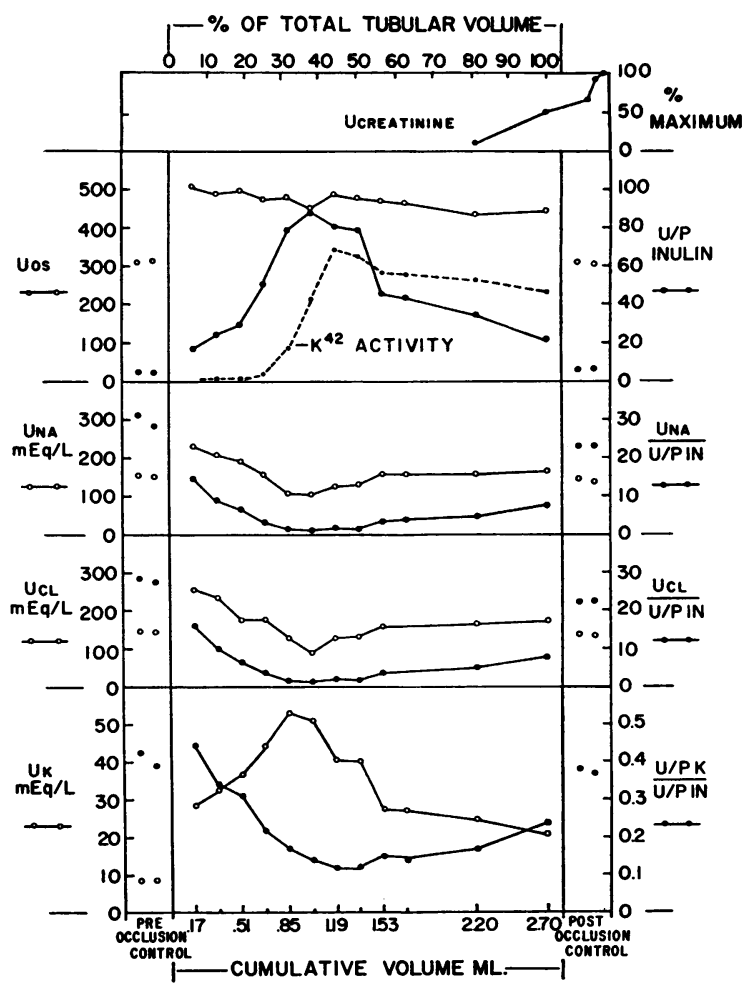

Fig. 3. STOP FLOW STUDY CONDUCTED DURING HYPERTONIC SODIUM CHLORIDE INFUSION (DOG $M$ ). Infusion: $200 \mathrm{mEq}$ per $\mathrm{L}$ of $\mathrm{NaCl}$; rate $=6.0 \mathrm{ml}$ per minute. $\mathrm{K}^{12}$ plotted as counts per minute on a relative scale. 
Further localization of the site of concentration of inulin is provided by relating this area to the concentration patterns for the various electrolytes during stopped flow. In each experiment maximum inulin concentration occurred at the site of the lowest chloride concentration, when the latter was divided by $\mathrm{U} / \mathrm{P}$ inulin to correct for changes in water content within the tubular fluid. That this relationship is not solely due to the high $\mathrm{U} / \mathrm{P}$ inulin in those specimens is indicated by the fact that the lowest absolute concentrations of sodium and chloride occurred in the same or adjacent specimens. It is therefore apparent that during stop flow considerable reabsorption of sodium chloride occurs in an area identical to or in close proximity to the site of maximal concentration of inulin. Another method for the localization of these effects has been the intracortical injection of $\mathrm{K}^{42} \mathrm{Cl}$ during stop flow. This has been done during sodium chloride and sodium sulfate diuresis. In each case (Figures 3 and 4) the appearance of high $\mathrm{K}^{42}$ activity coincided

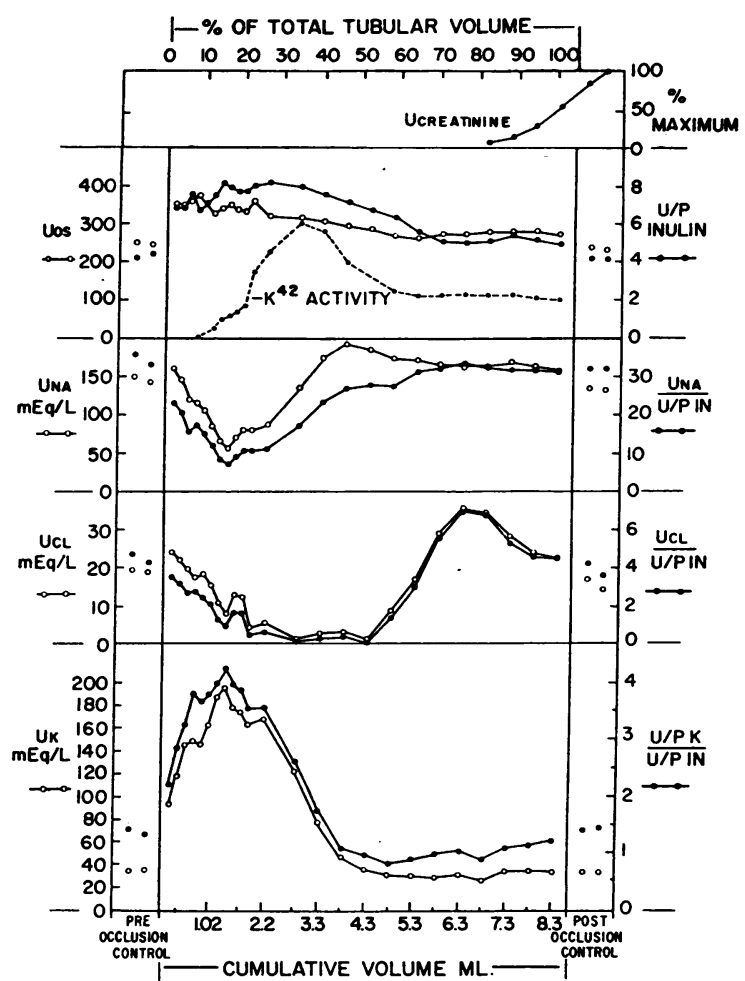

Fig. 4. STOP FLOW STUDY CONDUCTED DURING SODIUM SUlFATE DIURESIS (DOG $P$ ). Infusion: 120 mmoles per L. $\mathrm{Na}_{2} \mathrm{SO}_{4}, 40 \mathrm{mEq}$ per $\mathrm{L}$ of $\mathrm{KCl}$, plus acetazolamide; rate $=6.0 \mathrm{ml}$ per minute.

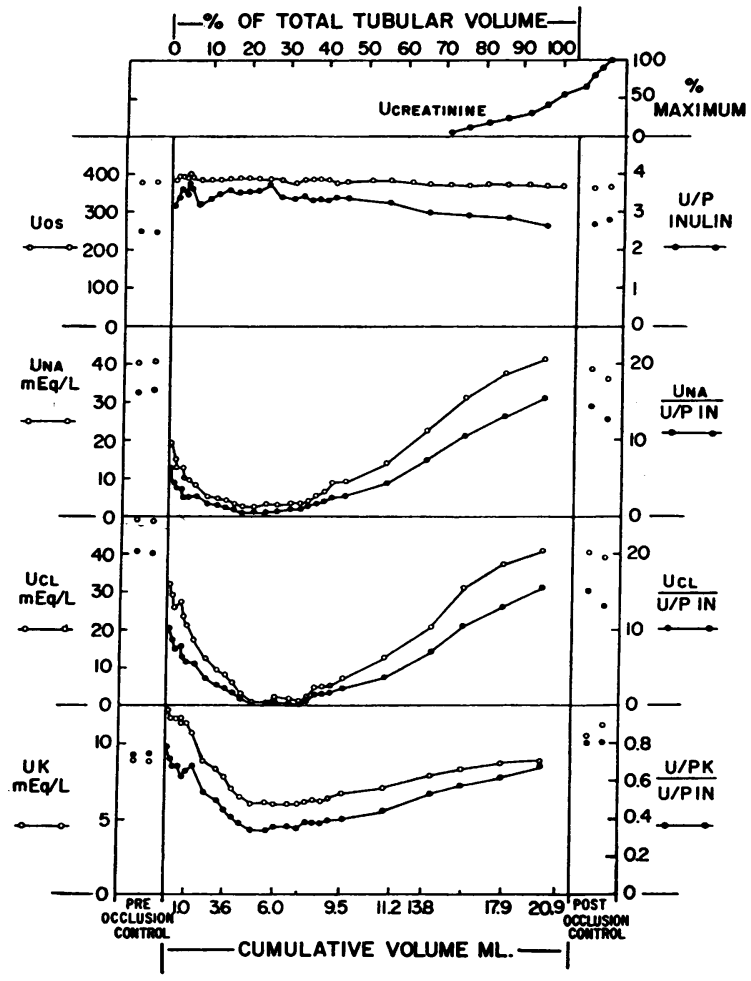

Fig. 5. StOP FLOW STUDY CONDUCTED DURING MANNITOL DIURESIS (DOG $\mathbf{K}$ ). Infusion: 15 per cent mannitol plus $30 . \mathrm{mEq}$ per $\mathrm{L}$ of $\mathrm{NaCl}$; rate $=10 \mathrm{ml}$ per minute.

with the area of maximum inulin concentration. This suggests that the site of concentration of inulin was in that segment of the distal nephron contained within the renal cortex, the distal convoluted tubule.

\section{Concentration patterns of electrolytes during stop flow}

A. Sodium and chloride. The concentration patterns for sodium and chloride shown in Figure 3 are characteristic of those observed during stop flow performed during sodium chloride diuresis. As has been noted, minimal concentrations are observed in or closely adjacent to those samples in which $U / P$ inulin and $K^{42}$ activity are at a maximum. More distal specimens contain a higher concentration of these ions. A similar pattern of distal sodium chloride concentrations is present in dogs infused with hypertonic mannitol (Figure 5).

During stop flow, the sodium and chloride concentrations, corrected for inulin, are consider- 
ably lower in the most distal specimen than in the previous control urine. The absolute concentrations, that is, uncorrected for inulin, may be lower than the control values in experiments done during mannitol diuresis (Figure 5). These observations suggest that reabsorption of sodium chloride occurs throughout the collecting duct. However, this concentration difference might also be explained by expansion of the intratubular volume in the most distal segment by fluid from a more proximal area, which had been exposed to the region of sodium transport and therefore contained very low concentrations of sodium and chloride. Consequently, these data can not be interpreted as unequivocal evidence for sodium and chloride reabsorption in the terminal part of the collecting duct system.

Because of difficulties in interpretation, the patterns of sodium and chloride concentration from specimens derived from the proximal convoluted tubule during stop flow are not dealt with in this report.

B. Potassium. A distal secretory site for potassium can be readily demonstrated by the stop flow technique. To facilitate the attainment of $\mathrm{U} / \mathrm{P}$ potassium over $\mathrm{U} / \mathrm{P}$ inulin ratios greater than 1 , the sodium salt of a nonreabsorbable anion has been infused. Figure 4 shows the result of a study in which 120 mmoles per $\mathrm{L}$ of $\mathrm{Na}_{2} \mathrm{SO}_{4}$ and $40 \mathrm{mEq}$ per $\mathrm{L}$ of $\mathrm{KCl}$, as well as acetazolamide, were infused. The $U / P$ potassium concentration ratio, corrected for inulin, rose to a value exceeding 4.0 in the distal tubule, considerably above the free flow ratio of $1.3 . \mathrm{K}^{42}$ was injected into the renal cortex during the period of ureteral occlusion. The corrected potassium concentration exceeded free flow values in all specimens from the distal 40 per cent of the tubular system, including those in which $\mathrm{K}^{42}$ activity was maximal. As shown in Figure 4, the maximum potassium concentration appeared distal to the isotope peak. The data suggest that secretion of potassium occurred in the distal convoluted tubule and at a more distal site, in the collecting ducts.

In both experiments in which sodium sulfate was infused, that specimen containing the highest $U / P$ potassium over $U / P$ inulin ratio also contained the highest absolute potassium concentration. As shown in Figure 3, a maximum potassium concentration is observed during sodium chloride diuresis which corresponds closely in location to that occurring during sulfate infusion. Whereas correction for inulin concentration obliterates this peak observed during sodium chloride diuresis, it is probable that this correction, as applied to potassium, is misleading. As the fluid in that segment of the tubule in which potassium secretion occurs remains in prolonged contact with the epithelium, during stop flow, it is probable that some maximal intraluminal potassium concentration is achieved. If so, the absolute potassium concentration, at the site of secretion, is independent of the movement of water out of the tubule, and thus of the intraluminal inulin concentration. Consequently, the absolute potassium concentration in distal tubular specimens may well be more representative of events occurring within the tubular lumen during the period of ureteral occlusion than are the "corrected" values.

As shown in Figures 3 and 4, the potassium concentrations in specimens from the most distal portion of the tubule are considerably higher than those observed in the previous control periods. This suggests that secretion of potassium occurs throughout the collecting duct system, but, as with the question of sodium chloride reabsorption in that area, the possibility that reabsorbed water from the most distal specimens has been replaced by potassium-rich fluid from higher in the tubule cannot be excluded. The data suggest that the site of maximal secretion is proximal to the terminal collecting ducts, and includes the distal convoluted tubule.

In stop flow performed during mannitol diuresis, the potassium concentration remains at low levels throughout the distal tubular system (Figure 5), and no peak comparable to that observed in sodium sulfate or sodium chloride diuresis is seen. The lowest concentrations occur in those specimens in which the sodium and chloride concentrations are at a minimum. In contrast, maximum potassium concentrations are observed in the same or in a closely adjacent area when ureteral occlusion is carried out during sodium chloride or sulfate diuresis.

\section{DISCUSSION}

As stated previously, the technical shortcomings of the stop flow method preclude precise lo- 
calization of certain tubular functions. During experiments performed during water or sodium chloride diuresis, it is expected that reabsorption of water in the distal tubular segments will result in a movement of the intratubular fluid column in a distal direction during the period of stop flow. Consequently various concentration patterns are best evaluated in relation to one another rather than in relation to their absolute location among the serial specimens collected after release of occlusion. An attempt at absolute location of functions occurring in the distal convoluted tubule has been made by the use of $\mathrm{K}^{42}$ labeling, however. Some movement of labeled fluid from the distal convolution toward a more distal site might be anticipated because of continued water reabsorption in the latter area. It has been observed, however, that the initial isotope peak appears at essentially the same point in water diuresis (38 per cent of the total tubular volume) as in sodium chloride or sulfate diuresis, despite the fact that relatively more water reabsorption occurs in the terminal collecting ducts during water diuresis, as evidenced by the marked increment in inulin concentration in the initial stop flow specimens. This suggests that the short time interval between injection of the isotope and starting urine flow minimizes migration of the labeled tubular fluid.

It is generally agreed that vasopressin increases water permeability in the distal convoluted tubule where osmotic equilibration of hypotonic precursor fluid with isotonic interstitial fluid and plasma results (11). Presumably vasopressin has a similar effect in the collecting ducts, where concentration of the urine is achieved by diffusion of water along an osmotic gradient created by the transport of sodium into the medullary interstitial fluid. The present data are fully compatible with the view that vasopressin has such an action in the distal convoluted tubule. The marked rise in inulin concentration during the period of ureteral occlusion (Figure 3 ) denotes a considerable loss of water from the tubule lumen, and the data suggest that this has occurred in the region of the distal convolution. In contrast to this effect observed during hypertonic sodium chloride infusion, no similar peak in inulin concentration occurs during water diuresis (Figure 2 ). In fact, the absence of a detectable increase in $\mathrm{U} / \mathrm{P}$ inulin in the area of the distal convolution suggests a high resistance to net water movement in that area when vasopressin is absent.

During ureteral occlusion in dogs undergoing sodium chloride diuresis the maximal inulin concentration attained is 8 to 16 times greater than the free flow value. This increment can not be solely accounted for by osmotic equilibration of hypotonic precursor fluid with an isotonic interstitium $(11,12)$. The observation that sodium was reabsorbed in the same segment of the tubule appears to explain the marked increase in inulin concentration in samples from that area. Water diffuses out of the tubules, in the presence of vasopressin, as sodium chloride is transported out of the tubular fluid. A process comparable to that occurring in the proximal tubule is envisioned except that in the distal tubule the capacity for outward transport of sodium (or a restricted back diffusion) allows for more complete removal of sodium from the tubular fluid.

The association, apparently in the region of the distal convoluted tubule, of vasopressin-sensitive water permeability and a mechanism capable of transporting sodium (chloride) against a high electrochemical gradient has important implications concerning the ability of the kidney to elaborate a highly concentrated urine. These processes, acting in conjunction, will result in a considerable reduction in the volume of fluid delivered to the collecting ducts. The water reabsorbed in the process is readily removed by the vascular supply of the renal cortex. On the other hand, water diffusing from the collecting ducts will dilute the medullary interstitial fluid, and tend to dissipate the osmotic gradient created by the active transport of sodium into this area. Therefore, at any constant degree of water permeability of the collecting ducts, and constant rate of sodium transport into the medulla and blood flow through the capillary loops, the final osmolality of the urine will tend to vary inversely with the volume of fluid entering the collecting duct system per unit of time. Removal of water in the distal convolution also results in an increased urea concentration in the fluid entering the concentrating area. This will in turn effect an increased rate of diffusion of urea into the medullary interstitial fluid, with a resultant increase in its osmolality and that of the final urine (13). 
The relationship between the volume of fluid delivered to the collecting ducts and the final urine osmolality is emphasized by the studies of Berliner and Davidson (10). Hypertonic urine was elaborated, despite the absence of vasopressin, when filtration rate was sufficiently reduced in one kidney by controlled constriction of the renal artery. It was concluded that this procedure resulted in the delivery to the collecting ducts of a small volume of dilute urine, and that sufficient equilibration with a hypertonic interstitial fluid occurred to result in the excretion of hypertonic urine. That diffusion of water across the collecting ducts may occur in the absence of vasopressin is further indicated by the present study. The marked rise in $U / P$ inulin and osmolality observed in ureteral occlusion performed during water diuresis indicates that water diffused from collecting ducts to interstitium along an osmotic gradient. It is probable that this gradient was higher in water diuresis than in sodium chloride diuresis, because of the low osmolality of the tubular fluid in the former. As a result, the inulin concentration in the most distal specimen showed a greater increment above control levels in water diuresis (Figures 2 and 3 ).

During mannitol diuresis, because of the presence of nonreabsorbable solute, water movement out of the distal convoluted tubule, as well as the proximal tubule, is minimized, and a large volume of fluid enters the collecting duct system per unit of time. The rate of movement of water out of the collecting ducts into the medulla attains maximal values (14), and sodium and urea are washed out of the interstitial fluid $(6,15)$. The resultant decrease in osmolality of the interstitial fluid accounts for the limited osmolar U/P ratio attainable during mannitol diuresis and for the failure to achieve a significant increase in osmolality during ureteral occlusion. It has recently been proposed (6), however, that the latter observations can be accounted for by a decreased efficiency of the medullary countercurrent multiplier mechanism, resulting from a high rate of urine flow through the loops of Henle. According to this hypothesis, the resultant fall in osmotic gradient within the renal medulla leads to diminished water reabsorption from the collecting ducts, a conclusion which is incompatible with the high rates of solute-free water abstraction generally observed during mannitol diuresis.

The stop flow technique does not appear to demarcate processes occurring in the loops of Henle. Micropuncture studies have demonstrated that fluid entering the distal convolution is hypotonic to plasma, regardless of the final concentration of the urine $(11,12)$. No hypotonic samples appear in occlusion studies performed during $\mathrm{NaCl}$ diuresis, however, presumably because the fluid must subsequently pass through the distal convolution and the collecting ducts, where concentration occurs. The present technique does not distinguish a distinct area of sodium transport corresponding to that thought to be present in the ascending limb of Henle's loop (11). It instead suggests that this area is directly contiguous with the sodium transport mechanism present in the distal convoluted tubule.

The present study is compatible with sodium chloride reabsorption in the collecting ducts, in accord with the observations of Hilger, Klümper and Ullrich, obtained by microcatheterization of the collecting ducts of the hamster (16). Utilizing two catheters, fluid samples were withdrawn from two different sites at accurately determined distances from the tip of the papilla. Concentration differences between the proximal and distal samples were interpreted as representing alterations in the tubular fluid imposed by diffusion or active transport across the collecting duct epithelium. In repeated observations, the more distal specimen contained a higher inulin concentration and a lower sodium concentration than the sample obtained at a more proximal site. This was interpreted as evidence of active transport of sodium, although whether this was exclusively by means of cation exchange or transport in association with an anion, was not established. The possibility that sodium chloride transported from the collecting ducts contributes to the establishment of the osmotic gradient necessary for the concentration of the urine has therefore been considered. Outward transport of sodium chloride will dilute the remaining tubular fluid unless it is accompanied by water, in which case no change in osmolality will occur. It is possible that sodium transported from the collecting ducts contributes to the total sodium content of the medulla, but 
only that part of the interstitial sodium transported from some portion of the tubule which is relatively impermeable to water (such as the ascending limb of the loop of Henle) can be responsible for the establishment of the high sodium concentration necessary for the concentrating process. Sodium transport from the collecting duct may effect water removal from the tubular lumen, by the same process postulated for the distal convolution, and thus result in the delivery of a smaller volume of urine to the distal portion of the collecting duct system. Analyses of slices from concentrating kidneys $(15,17)$ indicate that urea reaches ever higher concentrations as the tip of the papilla is approached, indicating that urinary concentration proceeds in a progressive fashion down the medulla and that the maximum concentration is achieved at the terminal end of the duct system. Consequently, any process which progessively reduces the volume of tubular fluid during its transit down the collecting duct will enhance the degree of hyperosmolality attained in the final urine.

Previous studies, using the stop flow technique, have indicated a distal secretory site for potassium $(2,18)$. The present data are in accord with these observations. It has been suggested that a reabsorptive mechanism for potassium also exists in the distal nephron (18-20). This conclusion is based on the observation that, during mannitol diuresis, low potassium concentrations are found in specimens from the distal system. Similar observations during mannitol diuresis have been made in this laboratory. This finding presents an apparent paradox, since a secretory site can apparently be demonstrated in the same or in a closely contiguous area under other conditions. It is worthy of note, however, that the low potassium concentrations noted during mannitol diuresis are present in the same specimens which contain the lowest concentrations of sodium and chloride, and that the latter ions are virtually completely removed from distal urine in ureteral occlusion performed during mannitol diuresis. This association suggests that, if, as considerable evidence suggests $(21,22)$, potassium secretion occurs as a cation exchange process, the virtual absence of an exchangeable cation ( $\mathrm{Na}$ ) precludes appreciable potassium secretion into this urine specimen as it subsequently flows past the potassium secretory site. On the other hand, when $\mathrm{NaCl}$ or $\mathrm{Na}_{2} \mathrm{SO}_{4}$ is infused, the concentration of sodium in the tubular fluid never attains extremely low levels. Thus, in $\mathrm{NaCl}$ diuresis a concentration peak for potassium can be demonstrated in proximity to, and perhaps slightly distal to, the distal site of maximal $\mathrm{NaCl}$ transport. In $\mathrm{Na}_{2} \mathrm{SO}_{4}$ diuresis, secretion unequivocally occurs in the same area. It appears most likely then, that rather than demonstrating a distal reabsorptive site for potassium, ureteral occlusion during mannitol diuresis produces a change in the tubular fluid which prevents subsequent potassium secretion into a segment of the trapped fluid.

\section{SUM MARY}

1. Utilization of a modified technique for stop flow analysis has permitted study of distal renal tubular functions under a variety of experimental conditions, including water, sodium chloride, sodium sulfate, and mannitol diuresis.

2. In accord with previous studies, the data suggest that the epithelium of the distal convolution is highly permeable to water in the presence of vasopressin. In contrast, during water diuresis, a considerable restriction to the diffusion of water is exhibited in the same area. It has been shown that water diffuses out of the collecting ducts in the absence of vasopressin, as has been concluded by previous workers.

3. Sodium chloride reabsorption occurs in the region of the distal convoluted tubule. Under certain conditions this process may occur against a high electrochemical gradient. It has been demonstrated that vasopressin-dependent water permeability and sodium chloride reabsorption occur coextensively, apparently in the cortical area of the distal tubular system. This association results in an effective reduction in the volume of fluid delivered to the concentrating area, and consequently enhances the ability of the kidney to elaborate a highly concentrated urine.

4. Potassium secretion occurs in the distal tubular system during ureteral occlusion. It is suggested that previous conclusions as to the presence of a potassium reabsorptive mechanism in the distal tubule are erroneous, since the data were obtained under conditions in which the sodium con- 
centration of the tubular fluid was extremely low, thereby imposing a limit on subsequent cation exchange, potassium for sodium.

\section{REFERENCES}

1. Malvin, R. L., Wilde, W. S., and Sullivan, L. P. Localization of nephron transport by stop flow analysis. Amer. J. Physiol. 1958, 194, 135.

2. Pitts, R. F., Gurd, R. S., Kessler, R. H., and Hierholzer, $\mathrm{K}$. Localization of acidification of urine, potassium and ammonia secretion and phosphate reabsorption in the nephron of the dog. Amer. J. Physiol 1958, 194, 125.

3. Malvin, R. L., Wilde, W. S., Vander, A. J., and Sullivan, L. P. Localization and characterization of sodium transport along the renal tubule. Amer. J. Physiol. 1958, 195, 549.

4. Omachi, A., and Macey, R. I. Intratubular fluid movement in dog kidney during stop flow. Proc. Soc. exp. Biol. (N. Y.) 1959, 101, 386.

5. Kessler, R. H., Hierholzer, K., Gurd, R. S., and Pitts, R. F. Localization of diuretic action of chlormerodrin in the nephron of the dog. Amer. J. Physiol. 1958, 194, 540.

6. Malvin, R. L., and Wilde, W. S. Washout of renal countercurrent $\mathrm{Na}$ gradient by osmotic diuresis. Amer. J. Physiol. 1959, 197, 177.

7. Malvin, R. L., Sullivan, L. P., and Wilde, W. S. Stop flow analysis of renal tubule localization. Physiologist 1957, 1, 58.

8. Aprahamian, A. H., Vanderveen, J. L., Bunker, J. P., Murphy, A. P., and Crawford, J. D. The effect of anesthetic agents on water diuresis (abstract). J. clin. Invest. 1958, 37, 875.

9. Bowman, R. L., Trantham, H. V., and Caulfield, P. A. An instrument and method for rapid, dependable determination of freezing-point depression. J. Lab. clin. Med. 1954, 43, 310.

10. Berliner, R. W., and Davidson, D. G. Production of hypertonic urine in the absence of pituitary antidiuretic hormone. J. clin. Invest. 1957, 36, 1416.

11. Wirz, $H$. The location of antidiuretic action in the mammalian kidney in The Neurohypophysis, $\mathrm{H}$.
Heller, Ed. New York, Academic Press Inc., 1957, p. 157.

12. Gottschalk, C. W., and Mylle, M. Micropuncture study of the mammalian urinary concentrating mechanism: Evidence for the countercurrent hypothesis. Amer. J. Physiol. 1959, 196, 927.

13. Levinsky, N. G., and Berliner, R. W. The role of urea in the urine concentrating mechanism. J. clin. Invest. 1959, 38, 741.

14. Page, L. B., and Reem, G. H. Urinary concentrating mechanism in the dog. Amer. J. Physiol. 1952, 171, 572.

15. Levinsky, N. G., Davidson, D. G., and Berliner, R. W. Effects of reduced glomerular filtration on urine concentration in the presence of antidiuretic hormone. J. clin. Invest. 1959, 38, 730.

16. Hilger, H. H., Klümper, J. D., and Ullrich, K. J. Wasserrückresorption und Ionentransport durch die Sammelrohrzellen der Säugetierniere. Pflüg. Arch. ges. Physiol. 1958, 267, 218.

17. Ullrich, K. J., Drenckhahn, F. O. and Jarausch, K. H. Untersuchungen zum Problem der Harnkonzentrierung und Harnverdünnung. Pflüg. Arch. ges. Physiol. 1956, 262, 537.

18. Sullivan, L. P., Wilde, W. S., Malvin, R. L., and Vander, A. J. Site of renal transport of potassium as revealed by stop flow analysis. Fed. Proc. 1958, 17, 158.

19. Samiy, A. H. E., Brown, J. L., and Globus, D. L. Interrelations of tubular transport of magnesium, potassium and calcium. Fed. Proc. 1959, 18, 135.

20. Rees, S. B., Franklin, S. S., August, J. T., Small, J. H., Kendall, A. R., Merrill, J. P., and Gibson, J. G. Stop flow analysis of renal tubular potassium and phosphate flux. Fed. Proc. 1959, 18, 126.

21. Berliner, R. W., Kennedy, T. J., Jr., and Hilton, J. G. Renal mechanisms for excretion of potassium. Amer. J. Physiol., 1950, 162, 348.

22. Davidson, D. G., Levinsky, N. G., and Berliner, R. W. Maintenance of potassium excretion despite reduction of glomerular filtration during sodium diuresis. J. clin. Invest. 1958, 37, 548.

\section{SPECIAL NOTICE TO SUBSCRIBERS}

Post Offices will no longer forward the Journal when you move. Please notify The Journal of Clinical Investigation, Business Office, 333 Cedar Street, New Haven 11, Conn., at once when you have a change of address, and do not omit the zone number if there is one. 